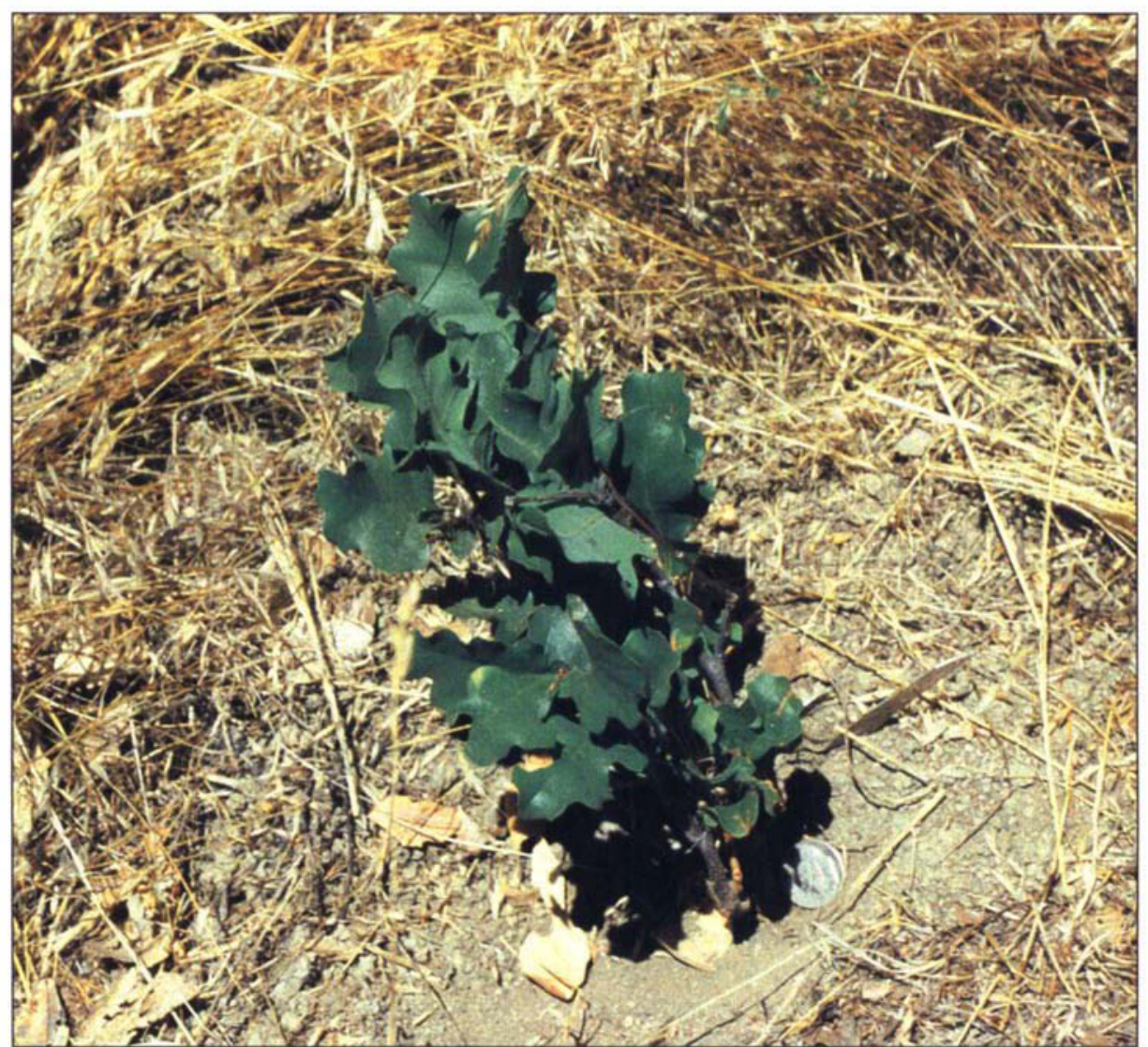

\title{
Blue oak seedlings may be older than they look
}

\author{
Ralph L. Phillips $\square \quad$ Neil K. McDougald $\sqcup$ Richard B. Standiford \\ William E. Frost
}

\begin{abstract}
A 4-year study indicates that native blue oak seedlings are probably much older than most people would think: Trees less than 6 inches tall could be 10 to 15 years old. Seedlings grow very slowly, if at all, during periods of drought. However, seedling mortality was highest during the year of aboveaverage rainfall.
\end{abstract}

Blue oak (Quercus douglasii) trees are a valuable economic and aesthetic natural resource in the Sierra Nevada foothills. The natural regeneration of these trees may not be adequate in some locations; consequently, it is of concern
The oak seedling at left is 8 to 10 inches tall and 12 to 16 years old. Below is a 6-to 8-inch-tall seedling estimated to be 10 to 15 years old.

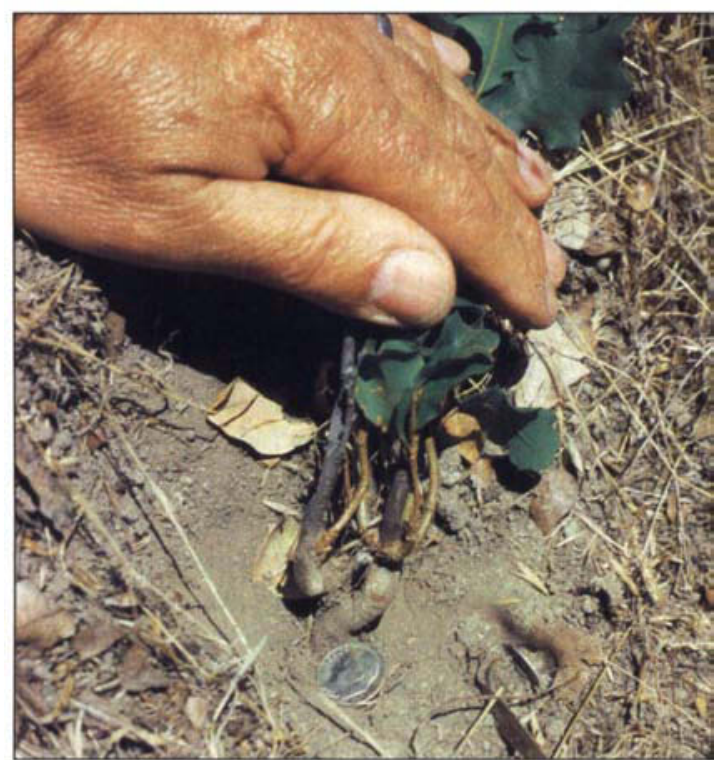

contributing factors, there is limited biological information to show what factors are influencing blue oak seedling survival. A study was initiated in 1989 to try to uncover the fate of small seedlings and to identify some factors that could be affecting seedling survival in the foothills of Kern County.

A drought extending from 1986 to 1992 coincided with establishment of this long-term study. Due to this climatic event, it will be possible to evaluate the effects of drought on blue oak seedling survival in another study.

\section{Site selection}

Much of the oak woodland acreage in Kern County was evaluated for potential study sites during summer 1989. We used three criteria in site selection: (1) the site had to be large enough to accommodate four 0.01-acre replications; (2) each replication had to contain at least 25 seedlings (less than 1 foot tall) and; (3) each site had to be in the savanna oak woodlands. The 
three sites were characterized using Monitoring California Annual Range Vegetation, Leaflet No. 21086, which defines seedlings as trees that do not exhibit mature characteristics. For our study, a seedling was defined as a tree less than 1 foot tall.

Site 1 was located in Section 28 of T29S, R32E at 3,560 feet elevation. The site is characterized by a $10 \%$ slope, N44W aspect, moderate residual dry matter (RDM) and a $38 \%$ blue oak canopy. Of the blue oak seedlings present, $48 \%$ had little or no hedging, $25 \%$ were moderately hedged and $27 \%$ were closely hedged.

Site 2 was located in Section 17 of T27S, R31E at 4,320 feet elevation. This site had a 10\% slope, N20E aspect, high RDM and a $25 \%$ blue oak canopy. None of the seedlings at this site showed signs of being hedged.

Site 3 was located in Section 11 of T29S, R31E at 3,960 feet elevation. The site is characterized by a $33 \%$ slope, N40E aspect, high RDM and a 51\% blue oak canopy. Seventy-four percent of the blue oak seedling present had little or no hedging, $19 \%$ were moderately hedged and $7 \%$ were closely hedged.

Site 1 had five replications and Sites 2 and 3 had four replications each. The number of seedlings per replication ranged from 25 to 128 . Altogether, 604 seedlings were marked with permanent identification numbers consisting of site, replication and individual plant. All seedlings found within each replication were evaluated.

We recorded initial height and evaluated all of the trees in the study every summer, shortly after the annual vegetation had dried up (late June or early July) and again each fall in midto-late September. During the evaluation, seedlings were classified as either present or absent. If they were present, it was noted whether they had green leaves or did not. If a seedling was present without green leaves for two consecutive years, or if it disappeared, it was classified as dead.

Since a number of the small seedlings had fairly large root-crown diameters, we suspected they were several years old. Therefore, during the summer of 1990 , a study was initiated to try to estimate the age of these small seedlings. Fifteen seedlings (not from the original 604 seedling) were sacrificed from each site. Each seedling was measured for shoot length, number of shoots and root-crown diameter. Cross sections were made of the root-crown area and growth rings were counted using a dissecting microscope. Regression analysis was conducted on the sacrificed seedlings by site for seedling height versus growth-ring counts and

TABLE 1. Site means for initial seedling height, change in seedling height between 1989 and 1993 and percent of seedling present in 1993

\begin{tabular}{|c|c|c|c|}
\hline Location & $\begin{array}{l}\text { Initial } \\
\text { seedling } \\
\text { height }\end{array}$ & $\begin{array}{c}\text { Change in } \\
\text { seedling height } \\
\text { between } 1989 \& 1993\end{array}$ & $\begin{array}{l}\text { Seedling found in } 1989 \\
\text { that were } \\
\text { still alive in } 1993\end{array}$ \\
\hline & \multicolumn{2}{|c|}{ 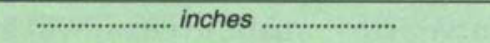 } & $\%$ \\
\hline Site 1 & $9.99 \mathrm{a}$ & $-0.17 b$ & $81.75 a$ \\
\hline Site 2 & $3.53 a$ & $0.65 a$ & $84.12 a$ \\
\hline Site 3 & $3.84 a$ & $-1.21 c$ & $70.98 a$ \\
\hline
\end{tabular}

'Values within columns with different letters were different at $P \leq 0.05$. Duncan's multiple range was used to test for differences between means.

TABLE 2. Percent of seedling in approximate age groups by sites

\begin{tabular}{|c|c|c|c|c|c|c|}
\hline \multirow[b]{2}{*}{ Location } & \multirow[b]{2}{*}{ Average age } & \multicolumn{4}{|c|}{ Age groups in years } & \multirow[b]{2}{*}{26 and older } \\
\hline & & $1-10$ & $11-15$ & $16-20$ & $21-25$ & \\
\hline & years & \multicolumn{5}{|c|}{ …1.1.1.1. } \\
\hline Site 1 & $14.52 \mathrm{a}$ & $52.72 a$ & $19.90 \mathrm{a}$ & $9.36 \mathrm{a}$ & $7.39 a$ & $10.56 a$ \\
\hline Site 2 & $5.23 b$ & $98.39 \mathrm{~b}$ & $1.00 \mathrm{~b}$ & $0.61 \mathrm{a}$ & $0.00 a$ & $0.00 \mathrm{a}$ \\
\hline Site 3 & $7.15 \mathrm{~b}$ & $88.78 \mathrm{~b}$ & $6.88 \mathrm{ab}$ & $1.11 \mathrm{a}$ & $1.67 \mathrm{a}$ & $1.56 \mathrm{a}$ \\
\hline
\end{tabular}

-Values within columns with different letters were different at $P \leq 0.05$. Duncan's multiple range was used to test for differences between means.

root-crown diameter versus growthring counts. Only root-crown diameter versus growth-ring counts were statistically significant. The regression equation from each site was used to estimate the age of seedlings in the respective site.

The shoot height and root-crown diameter were measured on each of the surviving seedlings during the early summer of 1993. All data was analyzed using an analysis of variance; a Duncan's multiple range was used to test for differences between means.

\section{Seedling height}

The mean initial seedling height for the three sites were 9.99 inches at Site $1,3.53$ inches at Site 2 and 3.84 inches at Site 3 . There were no significant differences between site means, even though average seedling height at Site 1 was considerably taller than the average seedling height for Sites 2 and 3.

The change in seedling height between 1989 and 1993 was small, but there was a significant difference between sites (table 1). Site 2 was the only site where seedlings increased in height ( 0.65 inch). Site 1 showed a slight decrease in height ( -0.17 inch); seedling at Site 3 showed a considerable loss in height ( -1.21 inches).

Most years, green shoots were observed on some seedlings in the spring, but by fall these shoots had dried up and appeared to be dead. The average percent of seedlings at each site that had green leaves in the spring but had lost them by fall were $10.59 \%$ at Site $1,4.94 \%$ at Site 2 and $16.7 \%$ at Site 3 . The following spring, the dry shoot did not green up; instead, a new, usually shorter shoot pushed from the root. It appeared that these new shoots were shorter, possibly due to the extended drought.

All three sites were grazed, but at different times of the year. There was no evidence of large ungulate browsing on the oak seedlings at any of the sites during the study period. The characterization of the sites indicated there was some browsing of small oak trees; however, the browsing occurred in trees larger than 1 foot tall. (Several 


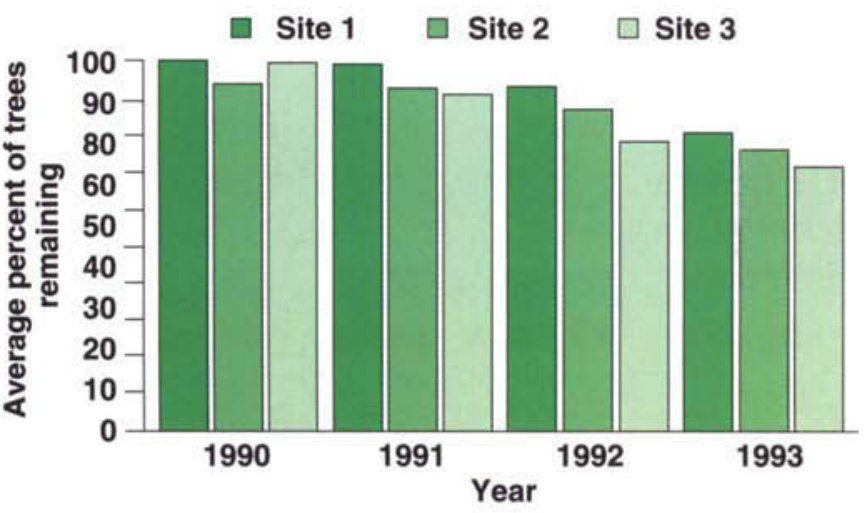

Fig. 1. Average percent of survival at three sites, 1990-1993.

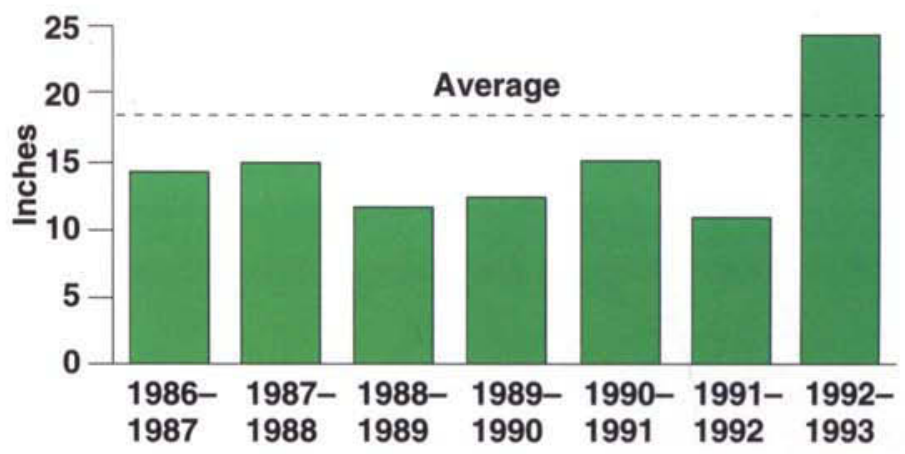

Fig. 2. Total annual rainfall recorded at a weather station in Glennville, 1986-1993. Average annual rainfall indicated by dotted line. studies have indicated that the browsing of small oak trees usually occurs when trees are taller than 1 foot.)

The initial heights of seedlings that died during the study were not significantly different between sites (Site 1: 3.09 inches; Site 2: 2.25 inches and Site 3: 1.93 inches).

\section{Seedling mortality}

Figure 1 shows the percent of original seedlings that survived at each site from 1990 to 1993 . Seedling mortality was similar between the three sites each year. There was no difference in seedling mortality between 1990 and 1992; however, mortality increased statistically for all three sites between 1992 and 1993.

There was very little rodent activity at Site 1, but Site 2 and Site 3 each had considerable gopher activity. However, rodent damage did not appear to be a major cause of seedling mortality. Only $3 \%$ of seedling mortality could be attributed to rodent activity.

Figure 2 shows annual rainfall from 1986-87 through 1992-93 recorded by the closest weather station, located in Glennville. The annual rainfall was below average for 2 years before the study and the 4 years during the study.

Of the 4 years evaluated, the greatest seedling mortality occurred during 1993, which had above-average rainfall. There are several possible explanations. One is that the criteria used to determine seedling death did not accurately reflect when death occurred, and there was possibly a 1- to 2-year delay in recording individual seedling mortality. Another explanation is that a single year's rainfall does not influence seedling mortality as much as a prolonged drought. (Tietje, Weitkamp, Jensen and Garcia (California Agriculture, November-December 1993), found that prolonged drought had a similar effect on the survival of oak sapling.)

Regression analysis indicated that there was a significant relationship between root-crown diameter and growth-ring counts. The $\mathrm{R}^{2}$ values for Sites 1,2 and 3 are $0.75,0.63$ and 0.77, respectively.

During other analysis of the age data, we found it was necessary to have a regression equation for each site. The equation for one site could not accurately estimate the ages of the trees at another site.

Table 2 shows the percent of seedlings in each approximate age group by site. Site 1 had the oldest stand of seedlings with only $52.72 \%$ in the 0 -to10-year age group, as compared to $98.39 \%$ for Site 2 and $88.78 \%$ for Site 3 . Again, Site 1 had a larger percentage of seedlings in the 11-to-15-year group $(19.90 \%)$ than Site 2, but not Site 3 (Site 2 had $1 \%$ and Site 3 had $6.88 \%$ ). The trend for Site 1, having a larger percentage of the older seedling than Sites 2 and 3 , continued through the 16-to20-year; the 21-to-25-year and the 26year-and-older groups, but these differences were not significant. Also, Site 1 had the higher mean age of 14.52 years, followed by Site 3 with 7.15 years and Site 2 with 5.23 years.
Seedlings were not categorized above 26 years because the ages of seedlings used to develop the regression equations did not extend beyond this point. However, several seedlings that had root-crown diameters of 1.13 inches and were only 6.5 inches tall could well have been older than 26 years.

\section{Blue oaks grow slowly}

This study indicates that there is considerable difference in age distribution of oak seedling between sites. Even very small plants, it appears, can be very old, some over 25 years of age. Also the study showed that blue oak seedling grow very slowly and, in many cases, actually decrease in height and still survive for several years. Since we did not measure the amount of native vegetation at each site, we cannot determine the influence that competition from native vegetation may have on oak seedling. The data from this study should be useful in establishing some baseline information for understanding the biology of blue oaks growing under natural conditions and limited rainfall, when compared to other areas of California.

R.L. Phillips is Range/Natural Resources and Livestock Advisor, UCCE Kern and Tulare Counties; N.K. McDougald is Natural Resources Specialist, UCCE Madera County; R.B. Standiford is IHRMP Program Manager, UC Berkeley; and W.E. Frost is Area Natural Resources Advisor, UCCE El Dorado County. 